\title{
EXCITONIC PHOTOVOLTAIC EFFECT IN A CYANINE DYE MOLECULAR ASSEMBLY ELECTRONICALLY COUPLED TO n- AND p-TYPE SEMICONDUCTORS
}

\author{
P. K. D. Duleepa Pitigala ${ }^{a}$, Maged M. Henary ${ }^{b, c}$, Eric A. Owens ${ }^{b, c}$, A. G. Unil Perera ${ }^{a, c}$, Kirthi \\ Tennakone ${ }^{a^{*}}$ \\ ${ }^{a}$ Department of Physics and Astronomy, Georgia State University, Atlanta GA. \\ ${ }^{b}$ Department of Chemistry, Center for Biotechnology and Drug Design, Georgia State University, Atlanta \\ GA. \\ ${ }^{c}$ Center for Diagnostics and Therapeutics, 100 Piedmont Ave SE Atlanta, GA.
}

\begin{abstract}
A solar cell of configuration $\mathrm{N}$-[DDD-----D]-P with a molecularly organized dye J-aggregate [DDD---D] electronically coupled to $\mathrm{N}$ - and P-type semiconductors is illustrated by fabricating a model device with $\mathrm{TiO}_{2}$ and $\mathrm{CuSCN}$ as the $\mathrm{N}$ - and P-type substrates and the thiocyanate of a cationic pentamethine cyanine dye as $\mathrm{D}$. Functional moieties in $\mathrm{D}$ anchors to $\mathrm{TiO}_{2}$ establishing electronic coupling and serving as a template for assembly of a J-aggregated film. Bonding of sulfur in thiocyanate anions at the other end of the aggregate create the electronic coupling needed to facilitates transfer of holes to CuSCN. The cell exhibits photoresponse originating from excitons generated in the bulk of the thick dye film as well as direct sensitized injection at the first interface. The dye molecular assembly is found to admit exciton transport over relatively long distances and significant hole mobility.
\end{abstract}

Key Words: Excitonic Solar Cell; Dye-sensitization; Hole mobility; Cyanine; Titanium dioxide

*Corresponding Author email: ktenne@ yahoo.co.uk 


\section{Introduction}

Organic- inorganic hybrid nanostructures have been studied extensively as potential systems for solar cell and other optical-electronic device applications. The prototype examples of photovoltaic devices of this category are: dyesensitized solid-state solar cells [1,2] (DSSSCs), extremely thin absorber (ETA) cells [3] and organic-inorganic hybrid $(\mathrm{OIH})$ heterostructures $[4,5]$. In a DSSSC, the excited molecules in a dye monolayer sandwiched between high bandgap $\mathrm{n}$ - and p-type semiconductors inject electrons and holes to respective regions, generating a photocurrent. In the analogous ETA cell, where the dye monolayer is replaced by a thin film of a low band-gap semiconductor, electrons and holes created in the thin film are efficiently transferred to $\mathrm{n}$ - and $\mathrm{p}$-type regions, provided film thickness does not exceed the carrier diffusion length $[6,7]$. Organicinorganic hybrid solar cell is basically a heterojunction of these two types of materials, where light absorbed by the organic component creates excitons that decompose at the interface, separating the charges [8]. In a thin film heterojunction, the thickness of the organic film is limited by the exciton diffusion length [9]. As the limitation of the thickness of light harvesting component restricts the overall light absorption cross-section, the performance of all the above systems are greatly improved by making the inorganic semiconductor, nanostructured to acquire a large surface area. Dye-sensitized and bulk heterojunction solar cells resorts to this strategy optimally. Furthermore in excitonic solar cells, the exciton diffusion length increases greatly if the organic film has an organized molecular arrangement. Generally, an organized molecular structure in the organic film will also enhance its carrier mobility, imperative for proper functioning of the cell. An advantage of organic-inorganic thin film systems is that, they more readily afford organized molecular assembly in the exciton transporting material compared to bulk heterojunction solar cells. Obviously, it is easier to build an organized molecular arrangement on a preset solid substrate (inorganic semiconductor) than to achieve such structure in a blend of two materials. This note describe an organic- inorganic hybrid solar cell of configuration n$\mathrm{TiO}_{2}$-[DDD----D]-p-CuSCN, where [DDD----D] is a molecularly organized thick film of a hole conducting cyanine dye electronically coupled to both $\mathrm{TiO}_{2}$ and $\mathrm{CuSCN}$. The cell exhibits photocurrents originating from exciton dissociation as well as direct dye-sensitized injection at $\mathrm{TiO}_{2} /$ dye, and dye/CuSCN interfaces. The dye assembly [DDD-----D] is found transport excitons over long distances of the order of $30 \mathrm{~nm}$.

\section{Experimental}

Films of $\mathrm{TiO}_{2}\left(1 \times 1 \mathrm{~cm}^{2}\right)$ were deposited on fluorine conducting tin oxide (FTO) glass plates $\left(1 \times 1.5 \mathrm{~cm}^{2}\right)$ by the method described previously for fabrication of DSSSCs [1]. Briefly, the procedure is hydrolysis of titanium isopropoxide $(5 \mathrm{ml})$ in $75 \%$ propan-2-ol $(15 \mathrm{ml})$ and acetic acid $(5 \mathrm{ml})$ to form a colloidal $\mathrm{TiO}_{2}$ suspension. The hydrolyzed product is mixed with Degussa $\mathrm{P} 25 \mathrm{TiO}_{2}$ powder and the viscous slurry spread over the FTO plate. The plate is heated to $120^{\circ} \mathrm{C}$ for $10 \mathrm{~min}$ and after blowing off the loose crust of $\mathrm{TiO}_{2}$ particles not adhered to the FTO surface, film is sintered at $425^{\circ} \mathrm{C}$ for $10 \mathrm{~min}$. By repetition of the process, $\mathrm{TiO}_{2}$ film can be grown to a desired thickness. Such films are largely devoid of interconnected void channels leading the FTO surface, preventing short-circuiting at the FTO interface when a heterojunction is formed. The roughness of an $8 \mu \mathrm{m}$ thick film estimated by adsorption of a standard dye is of the order of 500 .

The cationic cyanine dye named E-65 (structure 3 shown in Fig. 1a) was synthesized by the scheme shown in Fig. 1a, which admits ready variation of the auxiliary ligands $[10,11]$. The polymethine precursor 1 (structure 1 shown in Fig. 1a) is synthesized by reacting equimolar amounts of mucobromic acid with aniline in warm ethanol. In parallel, the heterocyclic moiety is prepared by alkylation of 2, 3, 3trimethylindolenine using bromoethanol to generate the cationic intermediate 2 (Fig. 1a). The condensation reaction between 1 and 2 proceeds effectively in the presence of acetic 
anhydride and sodium acetate which also affords the acylation of hydroxyl groups to yield the final compound 3 (E-65). The dye in the bromide form is converted to the thiocyanate by boiling the dye powder in saturated solution of KSCN and separation of the dye thiocyante precipitating on cooling the solution.

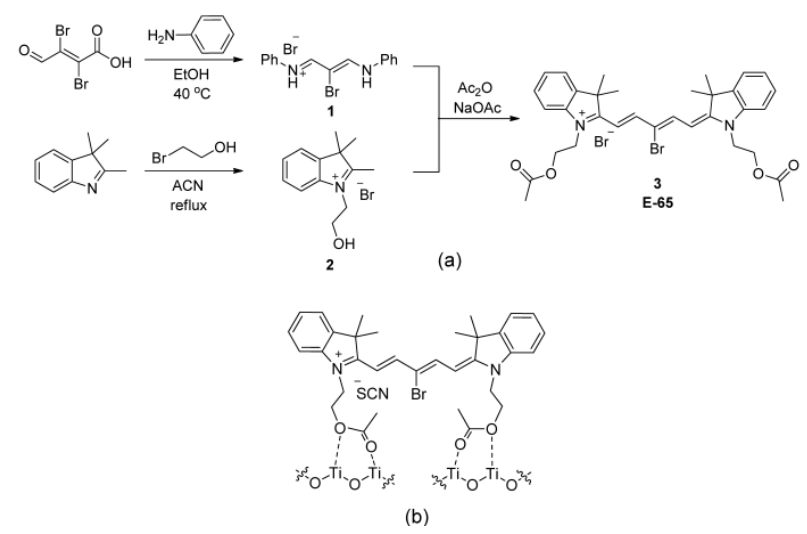

Fig. 1(a) Synthesis scheme of the dye E-65 and (b) its bidentate bonding to $\mathrm{TiO}_{2}$.

Dye was coated over the $\mathrm{TiO}_{2}$ film by the following procedure. The film is thoroughly cleaned with alkaline 50\% propan-2-ol followed by water and $99 \%$ propan-2-ol and plate dried at $120^{\circ} \mathrm{C}$. Dried plate is positioned vertically at the bottom of a glass tube (diameter $\sim 1.3 \mathrm{~cm}$ ) and the dye solution ( $\mathrm{M}$ in $90 \%$ ethanol) is poured over the plate to a height of about $4 \mathrm{~cm}$. The vessel was left in a constant temperature $\left(15^{\circ} \mathrm{C}\right)$ environment for several days to adsorb the dye. The monolayer thickness of the dye film was estimated by extracting dye from sample films and spectrophotometric estimation of the dye content. The film is dried in air at ambient temperature and p-CuSCN is drop coated over its surface from a solution in n-propyl sulfide and the film thickness is controlled by repeating the procedure. The performance of the cell decreases with the increase of the thickness of the $\mathrm{CuSCN}$ layer above the $\mathrm{TiO}_{2}$ film. However, to avoid scratching of the CuSCN surface, during graphite coating, the thickness of $\mathrm{CuSCN}$ above the $\mathrm{TiO}_{2}$ surface maintained $\sim 1 \mu \mathrm{m}$. The back electrode is formed by pressing a FTO glass plate to secure the contact. Painting graphite over the CuSCN surface improves the back contact. However, for comparison of the cell performance in front-wall (light incident on $\mathrm{TiO}_{2}$ ) and back-wall (light incident on $\mathrm{CuSCN}$ ) modes of illumination, graphite painting was avoided. The active area of the cells were $1 \mathrm{~cm}^{2}$ as $0.5 \mathrm{~cm}$ in the $1.5 \times 1 \mathrm{~cm}^{2}$ conducting glass plate has been left bare to connect the leads. The I-V characteristics of the cells were measured using a source meter at $1.5 \mathrm{AM}$ one sun illumination and photocurrent action spectra were recorded using a monochromator set-up.

The carrier mobility of the dye was determined by measuring the space-charge limited current. For this measurement, vacuum dried dye is pressed into a thin pellet between two stainless steel electrodes in a glass tube and connected to a d.c. voltage supply, sufficient to obtain a measurable current avoiding degradation of the material due to heating. Mobility is calculated from the Mott-Gurney equation[12],

$J=\frac{9 \varepsilon \mu V^{2}}{8 L^{3}}$

where $\mathrm{J}=$ current density, $\mu=$ mobility, $\varepsilon=$ dielectric constant, $V=$ applied voltage, $\mathrm{L}=$ pellet length. The sign of the charge carrier was ascertained by fieldassisted thermoelectric tests using the same experimental set-up. Alternative heating of two electrodes and noticing direction of biasing which yields a higher current in the circuit enables determination of the sign of carrier. Method does not require heating of the electrodes to an excessive temperature as in direct thermoelectric tests. FTIR spectra of dye lightly coated to $\mathrm{TiO}_{2}$ and the non-adsorbing substrate GaAS were recorded to ascertain the mode bonding the dye to $\mathrm{TiO}_{2}$.

\section{Results and Discussion}

When the $\mathrm{TiO}_{2}$ film is exposed to a relatively dilute $\left(\sim 10^{-3} \mathrm{M}\right)$ solution of the dye E-65 for 30 $45 \mathrm{~min}$, the dye coverage approximates to a monolayer formed by chelation of dye 
molecules to the $\mathrm{TiO}_{2}$ surface. The two functional groups in the dye anchor bidentately to $\mathrm{TiO}_{2}$ as shown in Fig. 1b. Comparison of the FTIR spectra of the dye adsorbed $\mathrm{TiO}_{2}$, bare dye and bare $\mathrm{TiO}_{2}$ shows changes in the characteristic $\mathrm{C}-\mathrm{O}-\mathrm{H}$ bending and $\mathrm{C}-\mathrm{O}-\mathrm{H}$ stretching vibrations [13] in the region suggestive of dye binding to $\mathrm{TiO}_{2}$ in this manner. The absence of the $\mathrm{C}-\mathrm{O}-\mathrm{H}$ bending band at $\sim 1100 \mathrm{~cm}^{-1}$ and drastic reduction in the $\mathrm{C}-\mathrm{O}-\mathrm{H}$ stretching band at $1738 \mathrm{~cm}^{-1}$ in the dye adsorbed onto $\mathrm{TiO}_{2}$, indicate bidentate bonding of the dye.

$$
\begin{aligned}
& \text { (a) } \\
& -\mathrm{X}^{+}-\mathrm{SCN}^{-} \\
& -\mathrm{X}^{+}-\mathrm{SCN}^{-} \\
& -\mathrm{X}^{+}-\mathrm{SCN}^{-} \\
& -\mathrm{X}^{+}-\mathrm{SCN}^{-} \\
& -\mathrm{X}^{+}-\mathrm{SCN}^{-}
\end{aligned}
$$

\begin{tabular}{|c|c|c|}
\hline $\mathrm{K}^{+}-$ & $-\mathrm{SCN}=\mathrm{X}^{+}-\mathrm{SCN}^{-}$ & ${ }^{+}-\mathrm{SCN}^{-}$ \\
\hline-5 & $-X^{+}-\mathrm{SCN}=\mathrm{X}^{+}-\mathrm{SCN}^{-}$ & $\mathrm{CN}^{-}=\mathrm{X}^{+}-\mathrm{SCN}^{-}$ \\
\hline & $-X^{+}-S C N=X^{+}-S$ & $-\mathrm{X}^{+}-\mathrm{SCN}=\mathrm{X}^{+}-\mathrm{SCN}=\mathrm{X}^{+}-\mathrm{SCN}^{-} \rightarrow$ \\
\hline & $-\mathrm{X}^{+}-\mathrm{SCN}=\mathrm{X}^{+}-\mathrm{SCN}^{-}$ & $-\mathrm{X}^{+}-\mathrm{SCN}=\mathrm{X}^{+}-\mathrm{SCN}=\mathrm{X}^{+}-\mathrm{SCN}^{-}$ \\
\hline & $-\mathrm{X}^{+}-\mathrm{SCN}=\mathrm{X}^{+}-\mathrm{SCN}^{-}$ & $-\mathrm{X}^{+}-\mathrm{SCN}=\mathrm{X}^{+}-\mathrm{SCN}=\mathrm{X}^{+}-\mathrm{SCN}^{-}$ \\
\hline
\end{tabular}

Fig.2 (a) Formation of the first monolayer of dye on $\mathrm{TiO}_{2}$ by surface chelation of the dye cation $\mathrm{X}^{+}$and electrostatic bonding of $\mathrm{SCN}^{-}$(b) subsequent growth of the film via bonding of dye cations and $\mathrm{SCN}$ anions by ion-dipole and electrostatic forces.

In more concentrated solutions $(>0.05 \mathrm{M})$, the first monolayer forms almost instantly by surface chelation of dye cations and electrostatic bonding of the SCN anions (Fig. 2a). The subsequent slower growth of dye film proceeds as consecutive bonding of dye cations and SCN anions via dipole-ion and electrostatic forces respectively (Fig. 2b). An initial fast absorption to form a monolayer and subsequent slow assembly has also been observed in J-aggregate formation on metallic [14] and other semiconductor substrates [9]. The firm anchorage of the first monolayer serves as a template for growth of an organized film. Slow evaporation of the solvent during storage (determined by ambient temperature and height of the air column and diameter of the tube) assists maintenance of dye concentration at a sufficient level to continue the film growth via forward progression of the dye adsorption, i.e.

$\mathrm{X}^{+}+\mathrm{SCN}^{-} \leftrightarrow[\mathrm{XSCN}]_{\mathrm{ab}}$

where $\mathrm{X}^{+}$denote the dye (E-65) cation and $[\mathrm{XSCN}]_{\mathrm{ab}}$ dye molecules adsorbed onto the substrate. Obviously incorporation of $\mathrm{SCN}^{-}$into the solution by addition of $\mathrm{KSCN}$, accelerates the film growth via common ion effect. Highly organized $\mathrm{J}$ or $\mathrm{H}$ aggregated films of ionic dyes can be deposited by the above technique. Nature of the dye and substrate and deposition conditions determines the type of the aggregation (i.e. $\mathbf{J}, \mathrm{H}$ or a mixture of $\mathbf{J}$ and $\mathrm{H}$ ) and extent of disorder.

A schematic diagram illustrating construction of the cell and an element of the heterojunction interface are shown in Fig. 3(a) and 3(b) respectively. Bonding of the functional groups of the dye, anchors it firmly to $\mathrm{TiO}_{2}$, facilitating the necessary electronic coupling. As sulfur in SCN readily binds to $\mathrm{Cu}$ sites in solid copper compounds $[9,15,16]$, the electronic coupling of the organized dye film to the hole collecting $\mathrm{CuSCN}$ is also secured.

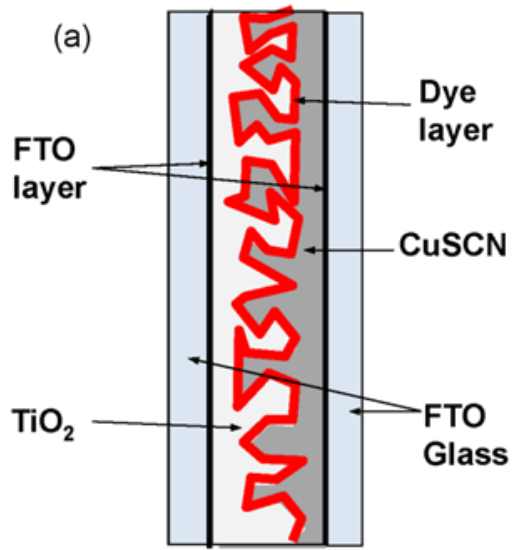

(b)

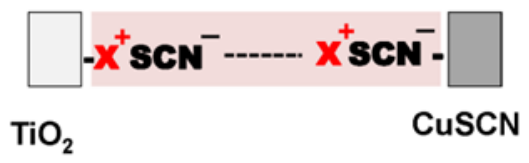

Fig.3 Schematic diagram indicating construction of the cell (a) and an element of the $\mathrm{TiO}_{2} /$ dye/CuSCN interfaces schematically depicting coupling of the organized dye aggregate to $\mathrm{TiO}_{2}$ and $\mathrm{CuSCN}$ (b). 


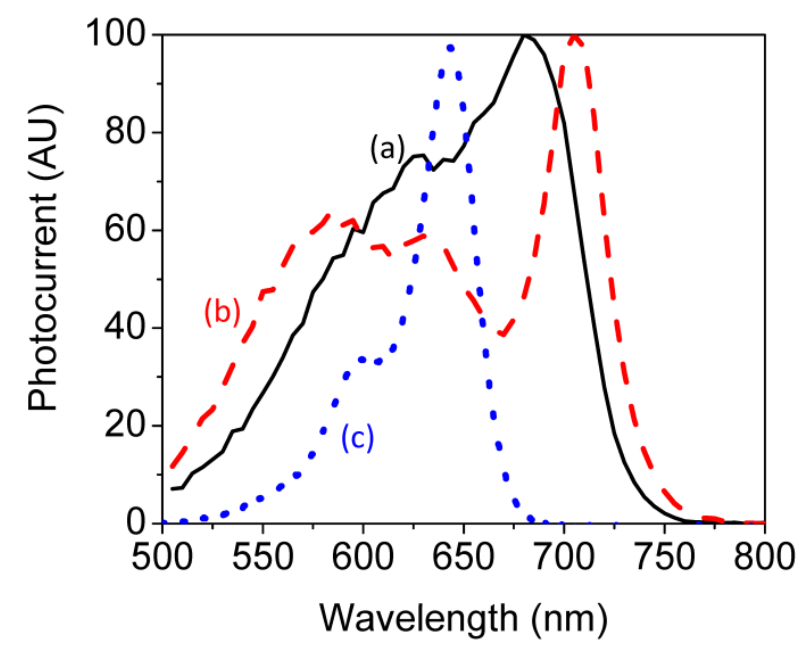

Fig.4 Normalized photocurrent action spectrum of the cell with a thick dye film (a) front-wall illumination (b) backwall illumination and (c) absorption spectrum of $0.001 \mathrm{M}$ solution of the dye.

The short-circuit photocurrent density $\left(\mathrm{J}_{\mathrm{sc}}\right)$ depended on the thickness of the dye film and in both front and back wall modes of illumination, $\mathrm{J}_{\mathrm{sc}}$ was found to be optimum in films much thicker than one monolayer, contrary to familiar dye-sensitized solar cells where the best photoresponse is generally seen at monolayer coverage of the dye. The observed effect in the thick film can be understood as a result of an excitonic contribution to the photocurrent.

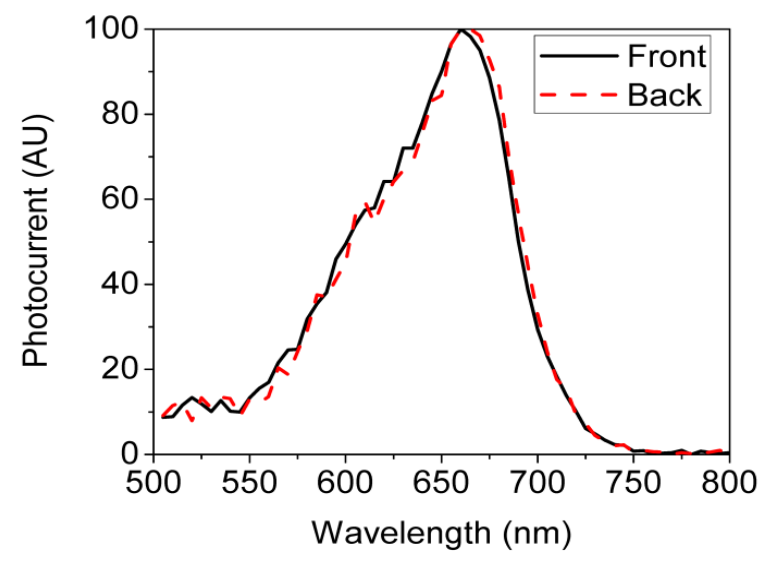

Fig.5 Normalized photocurrent action spectrum of a cell with a dye-monolayer in front and back wall modes
Like most cyanine dyes solid E-65 exhibits hole conduction [17], with a carrier mobility significantly high compared to familiar dyes. Possibly, the $\mathrm{Br}$ atom in methine chain acts as an electron acceptor releasing holes. The measurement of the variation of the space charge limited current with voltage bias is in good agreement with eqn.1, giving a mobility $\mu=(7.2 \pm 1.4) \times 10^{-3} \mathrm{~cm}^{2} \mathrm{~V}^{-1} \mathrm{~s}^{-1}$. When the cell is illuminated, HOMOs in dye molecules bonded directly to $\mathrm{TiO}_{2}$ excite electrons to LUMOs and transfer them to conduction band of $\mathrm{TiO}_{2}$ as in a normal DSSSC. As the dye is a p-type conductor, the hole released is transported along the thick dye layer to CuSCN. Again the excitons generated in the bulk decompose at the $\mathrm{TiO}_{2} /$ dye interface, separating electrons and holes to $\mathrm{TiO}_{2}$ and dye respectively and holes are transported across the dye layer to CuSCN. The photocurrent action spectra of a cell with thick ( 11 monolayers) dye film, in front and back wall modes of illumination are presented in Fig. 4. Both spectra have profiles extending from $500-775 \mathrm{~nm}$ with distinct differences. The front wall spectrum has a peak at $681 \mathrm{~nm}$ red-shifted from the absorption spectrum of the dye solution by $\sim 31 \mathrm{~nm}$. The cause of this peak is more intense direct sensitization at the $\mathrm{TiO}_{2} /$ dye interface combined with the excitonic contribution from light adsorbed in the bulk of the film. Whereas the back-wall spectrum displays a peak at $\sim 706 \mathrm{~nm}$ with a narrow profile red-shifted by $56 \mathrm{~nm}$ and a largely broadened blue-shifted peak structure at $\sim 579 \mathrm{~nm}$. It is interesting note that the back wall spectrum also shows a peak at $\sim 635 \mathrm{~nm}$ corresponding to direct sensitization at the dye/CuSCN interface. The back-wall mode spectrum could be understood as an effect originating from presence of $\mathrm{J}$ and $\mathrm{H}$ aggregated domains in the dye film. J-aggregates have narrow and redshifted absorption peaks compared to the monomer [18]. H-aggregates display the opposite behavior with broadened and blueshifted absorption peaks [18]. In the front-wall mode, this effect is partly masked by the contribution to the photocurrent from direct sensitization by the monomer anchored to the $\mathrm{TiO}_{2}$ surface. In the back wall mode, light 
incident on $\mathrm{TiO}_{2} /$ dye interface is not sufficiently intense to mask the photocurrent generated by excitons produced in the bulk of the thick film and decomposing at the $\mathrm{TiO}_{2} /$ dye interface and injecting electrons to $\mathrm{TiO}_{2}$ and conducting holes to $\mathrm{CuSCN}$. A cell with a monolayer thick dye film shows no distinction in front and back wall action spectra, both have peaks at $\sim 650 \mathrm{~nm}$, almost same as the peak absorption of dye in solution (Fig. 5). Again if the thick dye film of similar thickness is deposited by drop coating of the dye over the warmed $\mathrm{TiO}_{2}$ film instead of slow growth as in the previous experiment, the photocurrent action spectra in front and back wall modes do not demonstrate conspicuous distinction and the observed photo-response is weaker. Clearly the organized molecular assembly of the dye has been cause of the observed distinction in front and back wall action spectra and the enhanced photo-response. Generally, molecular organization greatly enhances fast diffusion of excitons [19]. The Fig. 6 shows the I-V curves of the cells with organized and disorganized thick dye layers and a monolayer. I-V parameters and peak wavelengths of the action spectra of different cells are summarized in the Table.1.

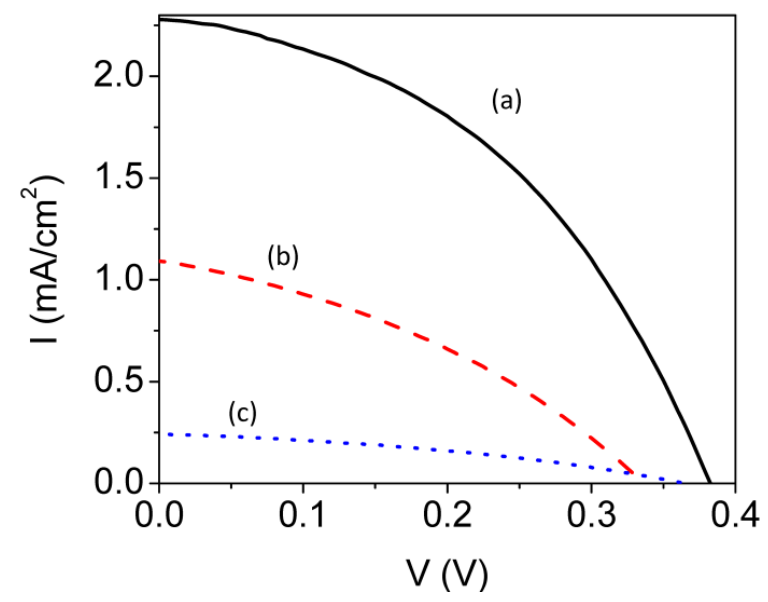

Fig. 6 I-V curves of the cells with (a) organized thick dye layer (b) disorganized thick dye layer (c) dye monolayer (Front wall illumination)

A severe problem in conventional DSSSCs is recombination at the points where inorganic nand p-type semiconductors are in direct contact. Imperfections in the dye monolayer frequently lead to this situation lowering the efficiency. In the present system, the thick dye layer naturally resolves this problem. It is important to note that distinction in the charge transfer processes originating from light absorbed by the first monolayer anchored to $\mathrm{TiO}_{2}$ and those in the bulk of the thick film. The bonding of the dye to $\mathrm{TiO}_{2}$ creates a charge transfer complex and kinetics of electron transfer from a dye molecule in the monolayer is a characteristic of the entirety of dye molecule and the charge transfer complex. Whereas light absorbed by dye molecules in the bulk emit exctions which decompose at the $\mathrm{TiO}_{2} /$ monolayer interface. There is evidence that such interfaces involving charge transfer couplings efficiently decompose excitons and the mobility of the hole in the Jaggregate suppresses back electron transfer [20].

Table.1 I-V parameters and peak photoresponse wavelengths of different cells (Front-wall illumination)

\begin{tabular}{|c|c|c|c|c|}
\hline Film & $\begin{array}{c}\mathrm{I} \\
\left(\mathrm{mAcm}^{-2}\right)\end{array}$ & $\begin{array}{c}\mathrm{V} \\
(\mathrm{mV})\end{array}$ & $\eta \%$ & $\begin{array}{c}\lambda_{\text {Max }} \\
(\mathrm{nm})\end{array}$ \\
\hline $\begin{array}{c}\text { Grown } \\
\text { organized }\end{array}$ & 2.3 & 374 & 0.4 & 687 \\
\hline $\begin{array}{c}\text { Drop coated } \\
\text { (disorganized) }\end{array}$ & 1.1 & 331 & $<0.15$ & 675 \\
\hline Monolayer & 0.3 & 350 & $<0.05$ & 658 \\
\hline
\end{tabular}

We have not yet succeeded in elucidating the morphological arrangement of $\mathbf{J}$ and $\mathrm{H}$ domains in the dye film. The simultaneous occurrence $\mathrm{J}$ and $\mathrm{H}$-aggregates has been reported in solid films with other dyes [21]. Two possibilities exist, i.e. regions composed entirely of either $\mathbf{J}$ or $\mathrm{H}$ aggregates connecting the two surfaces $\left(\mathrm{TiO}_{2}\right.$ and $\left.\mathrm{CuSCN}\right)$ or separated distributions across the thickness of the film. The latter morphology is somewhat detrimental to cell performance, for the following reason. During Jaggregation HOMO is moved upwards and LMUO downwards relative to their positions in the monomer, agreeing with observed red-shift in absorption spectrum [22-24]. The opposite would happen in an $\mathrm{H}$-aggregate, as this form molecular assembly leads to a blue-shift in absorption [22, 23]. Consequently, electron or hole transfer from an $\mathrm{H}$ to a J-region is permitted, but not the reverse. Thus an $\mathrm{H}$ - 
aggregated region in the middle of J-aggregate connecting $\mathrm{TiO}_{2}$ and $\mathrm{CuSCN}$ would impede carrier transport. The dye E-65 deposited on $\mathrm{TiO}_{2}$ is predominantly J-aggregated. The $\mathrm{Br}$ atom in the methine chain seems to enhance $\mathrm{J}$ aggregation by facilitation of appropriate molecular stacking. A cyanine analogous to E65 without a halogen atom in the methine chain was found to prefer $\mathrm{H}$-aggregation when deposited on $\mathrm{TiO}_{2}$ by the same procedure. The fact the action spectrum display greatly blue shifted broad peak, confirms that excitons generated in the $\mathrm{H}$-aggregated regions also participate in photocurrent generation, implying the presence of $\mathrm{H}$-aggregated domains connecting $\mathrm{TiO}_{2}$ and CuSCN interfaces.

The film thickness dependence of the photocurrent can be understood as follows: If $\Phi_{\mathrm{P}}$ $=$ photon flux incident on $\mathrm{TiO}_{2} /$ dye interface (front-wall mode). Flux at a distance $\mathrm{x}$ from the interface is $\Phi_{P} \exp (-x / \lambda)$, where $\lambda=$ mean free path of light. The exciton flux emanating from light absorbed in this element is $\lambda^{-1} \Pi_{P} \Phi_{P} \exp (-$ $\mathrm{x} / \lambda) \mathrm{dx}$, where $\Pi_{\mathrm{P}}=$ probability that an excited dye molecule will emit an exciton (Fig. 7).
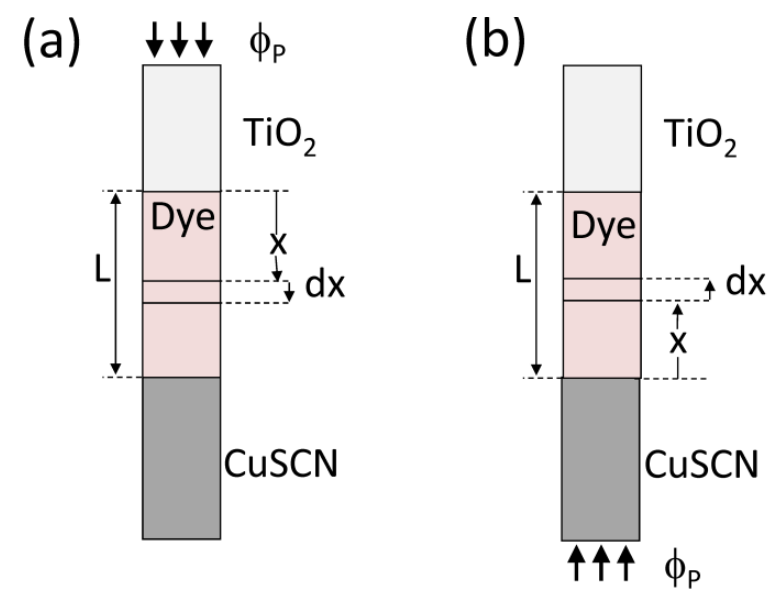

Fig. 7 Geometry of the front and back wall illumination

If a one dimensional model is assumed [8], half of excitons generated will travel in the backward direction and strike $\mathrm{TiO}_{2} /$ dye interface. The other half of excitons travelling in the forward direction will get reflected at dye/CuSCN $(\mathrm{R}=$ reflection coefficient) and the strike the dye $/ \mathrm{TiO}_{2}$ interface. As the exciton flux also attenuate in traversing through the dye film, the photocurrent $d I$ generated by the light absorbed in the element $\mathrm{dx}$ can be written as,

$$
\begin{aligned}
& d I=\frac{1}{2} e \lambda^{-1} \Pi_{D} \Pi_{P} \phi_{P} \exp \left(\frac{-x}{\lambda}\right) \\
& {\left[\exp \left(\frac{-x}{\Lambda}\right)+R \cdot \exp \left(\frac{x}{\Lambda}\right) \exp \left(\frac{-2 L}{\Lambda}\right)\right] d x}
\end{aligned}
$$

Where $\Lambda=$ exciton diffusion length, $L=$ thickness of the dye film, e = electronic charge, and $\Pi_{D}=$ probability of an exciton decomposing and injecting electrons to $\mathrm{TiO}_{2}$ and holes to $\mathrm{CuSCN}, R=$ excition reflection coefficient at the dye/CuSCN interface. Instead of reflection, excitons could also decompose at this interface injecting holes to $\mathrm{CuSCN}$. However, as the dye is not conducting electrons, holes will recombine with electrons residing in the dye at the interface. Integrating (3), the photocurrent $I$ is calculated as,

$$
\begin{aligned}
& I \approx \frac{1}{2} e \Pi_{D} \Pi_{P} \phi_{P}\left[1-\exp \left(\frac{-L}{\lambda}\right)\right] \\
& {\left[1+R \cdot \exp \left(\frac{-2 L}{\Lambda}\right)\right]}
\end{aligned}
$$

in the approximation $\Lambda>\lambda$. Total photocurrent is obtained by adding the contribution from direct sensitization by dye monolayer anchored to $\mathrm{TiO}_{2}$, which is independent of $L$. Similarly, the back wall mode photocurrent can be expressed as (Fig. 7),

$$
\begin{aligned}
& I=\frac{1}{2} e \Pi_{D} \Pi_{P} \phi_{P}(1+R) \\
& {\left[1-\exp \left(\frac{-L}{\lambda}\right)\right]\left[\exp \left(\frac{-L}{\Lambda}\right)\right]}
\end{aligned}
$$

Here, the photocurrent decrease more rapidly after film thickness reaches a maximum when $L$ 
$\sim \lambda[\ln (\Lambda / \lambda)]$. Knowledge of the extinction coefficient dye yield $\lambda \sim 16.6 \mathrm{~nm}$ and as the photocurrent is found to be optimum when the film is 11 monolayers corresponding to film thickness of $\sim 11 \mathrm{~nm}$, we obtain $\Lambda \sim 32 \mathrm{~nm}$.

\section{Conclusion}

A pentamethine cationic cyanine dye with two functional moieties binding to $\mathrm{TiO}_{2}$ and $\mathrm{a} \mathrm{Br}$ atom in the methine chain is synthesized. The functional moities surface chelate bidentately to $\mathrm{n}-\mathrm{TiO}_{2}$ establishing strong electronic coupling to the conduction band states. Bonding of dye to $\mathrm{p}$ $\mathrm{CuSCN}$ is facilitated by replacement halide anion by thiocyanate. Nanocrystalline $\mathrm{TiO}_{2}$ films exposed to a solution of dye under ambient conditions by mere control of solvent evaporation rate, admits deposition of predominantly J-aggregated thick films exhibiting fast exciton diffusion and detectable hole mobility. Model solar cell of the configuration n-TiO ${ }_{2}$-[DDD---D]-p-CuSCN with the thick organized dye film [DDD----D] demonstrate contributions to the photocurrent originating from excitons generated in bulk of the thick film and direct sensitized injection at the $\mathrm{TiO}_{2} /$ Dye interface. Low efficiency of the cell is attributed to insufficient hole mobility of the dye and/or exciton recombination at the interface. More stringent purification of the dye and improvement of film deposition technique to eliminate $\mathrm{H}$-aggregated domains will improve the efficiency. However, in order to attain orders of magnitude enhancement of the mobility, understanding of the mechanism of hole conduction and how it relates to the dye structure would be necessary to aim synthesis of more prospective dyes. Alternatively strategies may also be developed to enhance electronic carrier collection by modulating the inorganic film architecture [24]. Devices based on thick multi-layers organized molecules could turn out be promising systems for solar energy conversion $[25,26]$. The present system demonstrates that long distance exciton transport is possible, but unfortunately, the efficiency is severely limited by the poor carrier mobility.

The I-V parameters of the cell are rather low and several factors contribute to result. Thick dye layers are resistive because of the poor conductivity of the dye used. Again we have conducted measurements with cell of active area $1 \mathrm{~cm}^{2}$, compared to $0.25 \mathrm{~cm}^{2}$, generally used in most measurements. Because of the complexity of the system, reliable results cannot be obtained using smaller cells.

\section{Acknowledgements:}

This material is based upon work supported by, or in part by, the U.S. Army Research Laboratory and the U. S. Army Research Office under contract/grant number W911NF-12-20035 and NSF grant \# ECCS-1232184.Synthetic work was supported by the Georgia Research Alliance grant to $\mathrm{MH}$. $\mathrm{MH}$ and AGUP also appreciate the Georgia State University Center for Diagnostics and Therapeutics for their support.

\section{References}

[1] K. Tennakone, G.R.R.A. Kumara, A.R. Kumarasinghe, K.G.U. Wijayantha, P.M. Sirimanne, A dye-sensitized nano-porous solid-state photovoltaic cell, Semicond. Sci. Technol., (1995) 1689-1693.

[2] U. Bach, D. Lupo, P. Comte, J.E. Moser, F. Weissortel, J. Salbeck, H. Spreitzer, M. Gratzel, Solid-state dye-sensitized mesoporous $\mathrm{TiO} 2$ solar cells with high photon-to-electron conversion efficiencies, Nature, 395 (1998) 583-585.

[3] K. Ernst, A. Belaidi, R. Konenkamp, Solar Cell with extremely thin absorber on highly structured surface, Semicond. Sci. Technol., 18 (2003) 475-479.

[4] M. Wright, A. Uddin, Organic — inorganic hybrid solar cells: A comparative review, Sol. Energy Mat. Sol. Cells, 107 (2012) 87-111.

[5] M. He, F. Qiu, Z. Lin, Toward High-Performance Organic-Inorganic Hybrid Solar Cells: Bringing Conjugated Polymers and Inorganic Nanocrystals in Close Contact, J. Phys. Chem. Lett., 4 (2013) 17881796.

[6] P. Peumans, A. Yakimov, S.R. Forrest, Small molecular weight organic thin-film photodetectors and solar cells, J. Appl. Phys., 93 (2003) 3693-3723. 
[7] K. Tennakone, G.R.R.A. Kumara, I.R.M. Kottegoda, V.P.S. Perera, G.M.L.P. Aponsu, Nanoporous n-/selenium/p-CuCNS photovoltaic cell J. Phys. D: Appl. Phys., 31 (1989) 2326.

[8] M.-E. Ragoussi, T. Torres, Materiais Orgânicos Fotovoltaicos, Rev. Virt. de Quím., 7 (2015) 112.

[9] K. Tennakone, P.K.D.D.P. Pitigala, A.G.U. Perera, Exciton transport and electron mobility of organized aggregates of cationic dye thiocyanates, RSC Adv., 3 (2013) 2770-2775.

[10] M. Henary, M. Mojzych, Stability and Reactivity of Polymethine Dyes in Solution, in: L. Strekowski (Ed.) Heterocyclic Polymethine Dyes, Springer, Berlin Heidelberg, 2008, pp. 221-238.

[11] M. Mojzych, M. Henary, Synthesis of Cyanine Dyes in Heterocyclic Polymethine Dyes, in: L. Strekowski (Ed.) Heterocyclic Polymethine Dyes, Springer, Berlin Heidelberg, 2008, pp. 1-9.

[12] N.F. Mott, R.W. Gurney, Electronic Processes in Ionic Crystals, Oxford University Press, London, 1940.

[13] E. Bae, W. Choi, J. Park, H.S. Shin, S.B. Kim, J.S. Lee, Effects of Surface Anchoring Groups (Carboxylate vs Phosphonate) in RutheniumComplex-Sensitized $\mathrm{TiO} 2$ on Visible Light Reactivity in Aqueous Suspensions, J. Phys. Chem. B, 108 (2004) 14093-14101.

[14] A. Vujačić, V. Vasić, M. Dramićanin, S.P. Sovilj, N. Bibić, J. Hranisavljevic, G.P. Wiederrecht, Kinetics of J-Aggregate Formation on the Surface of Au Nanoparticle Colloids, J. Phys. Chem. C, 116 (2012) 4655-4661.

[15] B. Lange, M. Lovrić, F. Scholz, The catalytic action of adsorbed thiocyanate ions and thiourea in the electron transfer from glassy carbon to solid copper(I) selenide and copper(I) sulfide particles, J. Electroanal. Chem., 418 (1996) 21-28.

[16] C. Safarowsky, A. Spaenig, P. Broekmann, K. Wandelt, Reconstruction of a $\mathrm{Cu}(100)$ electrode in the presence of thiocyanate anions, Surf. Sci., 538 (2003) 137-146.

[17] A.K. Jana, Solar cells based on dyes, Journal of Photochemistry and Photobiology A: Chemistry, 132 (2000) 1-17.
[18] A. Eisfeld, J.S. Briggs, The J- and H-bands of organic dye aggregates, Chem. Phys., 324 (2006) 376-384.

[19] L.D.A. Siebbeles, A. Huijser, T.J. Savenije, Effects of molecular organization on exciton diffusion in thin films of bioinspired light-harvesting molecules, J. Mat. Chem., 19 (2009) 6067-6072.

[20] S. Verma, A. Ghosh, A. Das, H.N. Ghosh, Exciton-Coupled Charge-Transfer Dynamics in a Porphyrin J-Aggregate/TiO2 Complex, Chem. A Eu. J., 17 (2011) 3458-3464.

[21] G. de Miguel, M. Ziółek, M. Zitnan, J.A. Organero, S.S. Pandey, S. Hayase, A. Douhal, Photophysics of $\mathrm{H}$ - and J-Aggregates of IndoleBased Squaraines in Solid State, J. Phys. Chem. C, 116 (2012) 9379-9389.

[22] M. Kawasaki, T. Sato, Direct Voltammetric Observation of Reversible and Irreversible Oxidations of Two-Dimensional J-Aggregates of Cyanine Dye, J. Phys. Chem. B, 105 (2000) 796-803.

[23] K.C. Deing, U. Mayerhoffer, F. Wurthner, K. Meerholz, Aggregation-dependent photovoltaic properties of squaraine/PC61BM bulk heterojunctions, Phys. Chem. Chem. Phys., 14 (2012) 8328-8334.

[24] A. Vomiero, I. Concina, M.M. Natile, E. Comini, G. Faglia, M. Ferroni, I. Kholmanov, G. Sberveglieri, $\mathrm{ZnO} / \mathrm{TiO} 2$ nanonetwork as efficient photoanode in excitonic solar cells, Appl. Phys. Lett., 95 (2009) 193104.

[25] P.L. Marek, H. Hahn, T.S. Balaban, On the way to biomimetic dye aggregate solar cells, Energy \& Env. Sci., 4 (2011) 2366-2378.

[26] R. Hany, B. Fan, F.A. de Castro, J. Heier, W. Kylberg, F. Nüesch, Strategies to improve cyanine dye multi layer organic solar cells, Prog. in Photovolt.: Res. \& Appl., 19 (2011) 851-857. 